\title{
The effectiveness of a model-based health education program on genital warts preventive behaviors: a quasi-experimental study
}

\author{
Zahra Hosseini ${ }^{1}$, Niloofar Seyrafi ${ }^{2}$, Teamur Aghamolaei ${ }^{3}$, Shokrollah Mohseni ${ }^{1}$, Azin Alavi ${ }^{4}$ and \\ Sakineh Dadipoor ${ }^{5^{*}}$ (1)
}

\begin{abstract}
Background: Genital warts (GWs) are highly prevalent among Iranian women. GWs are not only highly infectious but are also followed by severe adverse effects, including the development of cervical cancer. Therefore, the present study aimed to explore the effect of an educational intervention based on the health belief model (HBM) on the adoption of GWs preventive behaviors by married women in Bandar Abbas, a city in the south of Iran.
\end{abstract}

Methods: A quasi-experimental intervention was conducted between 2019 and 2020 among 150 women participants (75 as the intervention and 75 as the control group). The sampling method was multi-stage clustering. The required data was collected using a reliable and valid tripartite questionnaire which explored demographic information, awareness, and HBM constructs. A total number of 15 educational sessions were held, each 90 min long. The control group received only one 90-min session. The final follow-up was completed three months after the intervention in November 2020.

Results: The two research groups had no statistically significant differences in terms of awareness, perceived susceptibility, severity, benefits, barriers, and self-efficacy before the intervention (in the pre-test) $(p>.05)$. After the educational intervention, the two groups showed statistically significant differences in all constructs except for the perceived benefits $(p<.001)$. In the intervention group, in the pretest (before the intervention), the behavior score was $2.77 \pm 2.59$, which was increased to $3.73 \pm .52$ after the intervention $(p<.001)$. In the control group, however, the difference was not statistically significant $(p=0.227)$.

Conclusion: The present findings showed that the educational intervention based on the HBM can improve the prevalence of GWs preventive behaviors in women. This education should be provided by experts at regular intervals in all healthcare centers.

Keywords: Genital warts, Human papillomavirus, Women, Health belief model

\section{Background}

HPV is a prevalent infection that is transmitted through sexual contact. It is related to cancers such as cervical, head and neck squamous cell cancer and anal cancer [1].

*Correspondence: mdadipoor@yahoo.com

${ }^{5}$ Infectious and Tropical Diseases Research Center, Hormozgan Health Institute, Hormozgan University of Medical Sciences, Bandar Abbas, Iran Full list of author information is available at the end of the article
HPV genotypes exceed 120 types. More than 40 of them affect the anogenital epithelium of men and women. About 14 HPV genotypes are called high risk as they can lead to cervical cancer and account for a great many cancers in the vagina, vulva, penis, anus, or oropharynx [2]. A number of low-risk HPV genotypes can lead to GWS (condyloma acuminate) [3]. About 70\% of cervical cancers are induced by HPV 16 and 18. Moreover, original author(s) and the source, provide a link to the Creative Commons licence, and indicate if changes were made. The images or other third party material in this article are included in the article's Creative Commons licence, unless indicated otherwise in a credit line to the material. If material is not included in the article's Creative Commons licence and your intended use is not permitted by statutory regulation or exceeds the permitted use, you will need to obtain permission directly from the copyright holder. To view a copy of this licence, visit http://creativecommons.org/licenses/by/4.0/. The Creative Commons Public Domain Dedication waiver (http://creativeco mmons.org/publicdomain/zero/1.0/) applies to the data made available in this article, unless otherwise stated in a credit line to the data. 
$90 \%$ of GWS are induced by genotypes 6 and 11 [4]. Several studies found a statistically significant correlation between GWs and some cancers in the reproductive system [5, 6]. A study reported that the incidence rate of cancers associated with genitals is higher in women afflicted with GWs [7].

GWs are among the most prevalent viral and infectious sexually transmitted diseases. About $27 \%$ of sexually active people suffer from the disease. A body of research shows that in $60 \%$ of cases, a single sexual contact via skin and oral mucosa can transmit the disease to the sex partner [8]. The related literature show that about 6.2 million new types of GWs occur annually in the 14-44-year-old population [9]. The findings on the prevalence of GWs in different countries have been quite divergent. One study reported the incidence rate of GWs among Indian women to be between 1.4 and 25\% [10]. Another study reported the prevalence of GWs in Italian and Philippine women to be $0.038 \%$ and $3.39 \%$, respectively [11]. The prevalence of GWs is high among Iranian women [1214]. A study in Iran showed that $20.8 \%$ of women who had been referred to the clinic for vaginal infection were diagnosed with GWs [13]. Another study showed that $47.3 \%$ of GWs occurred in the 24-30 year age group [15]. In their research on 851 Iranian women, Shafaghi et al. found that 265 subjects were afflicted with different types of HPV and some with GWs [16].

GWS are highly infectious, and about $65 \%$ of people who have infected sex partners get afflicted with the disease in 3-8 months [17]. GWs are not only highly contagious but also accompanied by clinical symptoms such as an itchy or pricking feel, pain, hemorrhage and the development of cervical cancer [18]. An early diagnosis might need no special treatment. Yet, diagnosis with GWs can have significant social and psychological effects on patients. A body of research showed that GWs can change the appearance of the vulva, causing embarrassment and anxiety and the quality of sexual relationships [10]. As there is no HPV vaccination yet in Iran, and sexual relationships are only acceptable for married women in the culture, the sexually transmitted infection test is quite a challenge for most women [19]. It seems that preventing infection is the best strategy in this region. Another study reported that preventing GWs-related high-risk behaviors can be effective in controlling the disease [18]. Moreover, preventing risky behaviors can largely contribute to women's awareness, attitude, and beliefs [20].

Several studies in Iran reported a low level of young women and girls' awareness of GWs and HPV. These studies also indicated that women are not educated properly and have limited knowledge of the hazards of the virus and its role in the occurrence of cervical cancer [13,
$21,22]$. In fact, only $8 \%$ of people afflicted with GWs use condoms [23]. However, in Hong Kong, 65\% of the population afflicted with HPV use condoms [24]. These facts and figures reveal the lack of GWs preventive behaviors in Iran. Another study showed that raising awareness of GWs can significantly help to reduce its epidemic [8]. Therefore, the first step to control the disease is to raise awareness of the infection and adopt the required preventive and protective behaviors. Presumably, awareness-raising affects people's attitude, susceptibility and perceived risks and, thus, plays a preventive role in affliction with GWs.

Intervention design is informed by health behaviours models and theories. The Health Belief Model (HBM) is one such model and has been shown to be effective in driving change in sexual behaviours [25-27]. If people perceive themselves as susceptible to the disease and perceive the benefits of staying away from infection, they are motivated to change their behaviors. The HBM encompasses the perceived benefits and barriers within its expected value framework. If the perceived benefits are more than perceived barriers, there are higher chances of adopting a healthy behavior $[28,29]$.

This model illuminates how one's perception can create a certain motivation or behavior. According to this model, in order to adopt the desired preventive behavior, people should first perceive themselves as susceptible to GWs, and then perceive the severity of the disease and the different physical, social, psychological and economic side effects through the cues to action from the surrounding environment or the inner world. They need to believe in the practicality of the GWs preventive program and perceive the benefits of the program and find the benefits of the behaviors more than the barriers. They should see the program as less costly and see themselves capable of showing preventive behaviors. This is undertaken as self-efficacy within the theoretical model. Taking all these into account, people are ready to show GWs preventive behaviors [29].

A body of research reported significant correlations between GWs and vulva, vagina, penis, anus, anogenital malignancies, head and neck cancers $[5,6,30]$. Considering the correlation between GWs and malignancies in genitals, the present research aimed to investigate the effect of an educational intervention based on the health belief model on the adoption of GWs preventive behaviors in women visiting healthcare centers in Bandar Abbas.

\section{Methods}

\section{Design and sampling}

The present quasi-experimental research with an experimental and a control group was conducted in 2019-2020. 
It aimed to explore the effect of an educational intervention based on the HBM on the adoption of GWs preventive behaviors through a 3-month follow-up among married women above 15 years old in Bandar Abbas, Iran.

\section{Setting}

The present research was carried out in Bandar Abbas, the capital city of Hormozgan Province in the south of Iran. This city is located in 27.19 latitudes and 56.28 longitudes and is located $9 \mathrm{~m}$ above sea level. Bandar Abbas has a population of 352,173 , which makes it the largest city in Hormozgan Province.

\section{Eligibility criteria}

The inclusion criteria were an age above 15 years, no history of sexually transmitted diseases, being married and being local to Bandar Abbas (born in the city or living there for at least ten years for cultural adjustment).

Signing an informed consent to take part was another inclusion criterion. The exclusion criteria were absence for more than two sessions, unavailability in the posttest, and the omission of incomplete questionnaires.

\section{Intervention and follow-up}

The questionnaires were (knowledge and HBM constructs) were submitted to participants in both the intervention and control groups before the experiment. The pretest results were used for a needs analysis of educational content, teaching methods and the number of sessions needed for education. The educational sessions were held for the intervention group in a friendly environment such as a local mosque or a healthcare center within a four month's period. The material to be taught was developed based on the learners' comprehension, reliance on valid sources, professors' comments and participants' views based on the HBM. In the short-term and long-term adverse effects of GWs (5) benefits of adopting GWs preventive behaviors (6) using useful strategies to remove barriers to adopting healthy behavior (7) motivating women to adopt GWS preventive behaviors and increasing self-efficacy. The details on the educational sessions are indicated in Additional file 1. Of note is that to our knowledge, Iranian women are less familiar with the term HPV. They mainly know HPV as only associated with GWs. Thus, the resent researchers tried to use GWs more, but developed the educational content of sessions so as to raise awareness of HPV in general. The control group received 1 educational session on how GWs are transmitted and the significance of personal healthcare in preventing the spread of the disease. Three months after the intervention, the posttest questionnaires were filled out in both research groups to assess the effectiveness of the intervention.

\section{Sample size estimation}

The present research aimed to compare the scores for HBM constructs between the control and intervention groups. Thus, a formula was used to estimate the sample size needed for acquiring information from two independent groups, as indicated below. In similar research entitled as "Investigating the effect of an educational intervention based on the HBM on administering the Pap test among women in Fasa," Khiali et al. [31]. Reported the mean and standard deviation of perceived severity in the intervention and control groups $20.86 \pm 2.13$ and $18.95 \pm 2.99$, respectively. The following formula was used with $\alpha=0.05\left(z_{1-\frac{\alpha}{2}} \simeq 2\right), \beta=0.2$ $\left(z_{1-\beta}=0.85\right)$. The least difference of means (the effect size) was 1 . The eventual sample size for each group was estimated at 73 in the formula. To be on the safe side, a total number of 75 participants was set for each research group.

$$
n=\frac{\left(z_{1-\frac{\alpha}{2}}+z_{1-\beta}\right)^{2}\left(\delta_{1}^{2}+\delta_{2}^{2}\right)}{\left(\mu_{1}-\mu_{2}\right)^{2}}=\frac{(2+0.85)^{2}(2.13+2.99)^{2}}{1}=73 \Rightarrow \approx 75
$$

total, 15 educational sessions were held (14 held by the first author and one by a gynecologist). There were six instructional groups. Each session was 40-60 min in length with a 10-min interval. The teaching techniques used included lectures, cooperative discussions, brainstorming, photos and movies. The following content was covered in the educational intervention: (1) familiarity with HPV infection, all symptoms of GWs, ways of transmitting GWs. (2) GWs risk factors (3) the significance of preventing the incidence of GWs (4)

\section{Sampling type}

In Iran, the sampling was done as multi-stage. In other words, in the first stage, the overall 20 comprehensive healthcare centers in Bandar Abbas were divided into five geographical regions (north, south, east, west, and center). Each geographical region included four comprehensive healthcare centers. In the second stage, two healthcare centers were selected randomly from each region (in total, ten comprehensive healthcare centers). In the third stage, five centers were randomly selected (1 
center from each geographical region) and assigned to the intervention group and 5 to the control group. Finally, in each center, the sample was selected from the visitors to healthcare centers. If they met the inclusion criteria, they were selected through convenience sampling method until the required sample size $(\mathrm{n}=15)$ was met.

\section{Data collection}

The pretest questionnaires were provided to subjects in both the control and intervention groups who had provided written consent to take part in the study. At the end of the 15th education session, both the control group and the intervention group completed the postintervention questionnaire. To facilitate the identification of the pre- and post-test questionnaires, the last four digits of each participant's mobile phone number and age were coded on the questionnaires. Each questionnaire took 20-25 min to complete. The researcher was not present during the questionnaire completion process. For illiterate participants, the content of the questionnaire was read out loud and answered with the least possible bias with the help of a member of the research team.

\section{Instrumentation and scoring system}

The questionnaire used in this research contained closed-ended questions to be answered on a Likert type: True/False/Don't Know. There were three parts to the questionnaire as introduced below.

\section{Part 1: Demographic information}

Participants' demographic information included their age described at two levels ( $\leq 30$ and $\geq 31$ ), education (below diploma, diploma, higher), husband's education (below diploma, diploma, higher), occupation (not working, working outside the home).

\section{Part 2: Awareness level}

There were 24 items about awareness of GWs. The reliability of this part of the questionnaire was tested by Farshbaf et al. among women in Tabriz City and was found to be $82 \%$ [32]. Items enquiring about the awareness of GWs were rated on a three-point Likert type (True, False, Don't Know).' A correct answer was scored as 1 and an incorrect answer was scored as zero. These items explored certain aspects of awareness, including how the disease can be transmitted, the symptoms of the disease and how to prevent GWs.

\section{Part 3: HBM constructs}

There were 6 sub-scales in this part of the questionnaire. "Perceived susceptibility" included 7 items an instance of which is "Despite taking genital care into account, I am still susceptible to genital warts". "Perceived severity" was tested with 5 items one of which is: "Affliction with GWs may make me infertile." "Perceived benefits" was rated on 7 items and explored the extent to which the participants perceived the benefits of an early diagnosis of GWs to prevent severe symptoms. An instance of the content is: "It did not cost me to adhere to health recommendations."

The "Perceived barriers" to the adoption of GWs preventive behaviors were tested along with ten items including "I feel embarrassed if others know I am afflicted with GWs." "Self-efficacy" was tested with six items to explore the participants' capability of showing GWs preventive behaviors. An instance is: "I am sure I can tolerate the little pain of the Pap test to take care of myself". Finally, the healthy behavior was tested with four items, including: "I follow genital healthcare advice to lower the chances of affliction with GWs."

The above-mentioned items were all tested on a 5-point Likert type: (1) strongly agree, (2) agree, (3) neutral, (4) disagree, (5) strongly disagree. At the end, the scores were not added up. Rather, they were calculated separately and reported for each participant. A higher score showed stronger feelings towards the construct. All subscales were positively related to GWs preventive behavior except for perceived barriers which was negatively correlated.

\section{Data quality assurance}

Pretested and structured questions were used as the data collection instrument after a review of the most recent related papers. All questionnaire items were answered as self-reports. These were pretested on 23 women with similar characteristics to the target population. Their comments were used to revise the questionnaire and better organize it. These participants were excluded from the main data collection phase. The first draft of the questionnaire was also checked by a panel of experts for readability, simplicity, relatedness and importance of content. Their comments were used to further revise the draft. The test-retest method was used to check the reliability. To this aim, the questionnaire was submitted at a two-week interval to 20 respondents who met similar conditions to the main participants. Then, the ICC index was used to check the consistency of scores from the first administration to the next. The estimated ICC was 0.83 .

\section{Ethical considerations}

A formal permission letter was obtained for data collection from the university deputy of research. Then, the target healthcare centers were visited. Upon admission, 
Table 1 Participants' demographic information in the research groups

\begin{tabular}{|c|c|c|c|c|}
\hline Variables & Total sample N (150) & Intervention group $(n=75)$ & Control group $(n=75)$ & $p$ value \\
\hline \multicolumn{5}{|l|}{ Age (years) } \\
\hline$\leq 30$ & $114(76 \%)$ & $54(72 \%)$ & $60(80 \%)$ & 0.014 \\
\hline$\geq 31$ & $36(24 \%)$ & $21(28 \%)$ & $15(20 \%)$ & \\
\hline \multicolumn{5}{|l|}{ Educational level } \\
\hline Below diploma & $31(20.66 \%)$ & $20(26.7 \%)$ & $11(14.7 \%)$ & 0.148 \\
\hline Diploma & $67(44.66 \%)$ & $29(38.7 \%)$ & $38(50.7 \%)$ & \\
\hline Higher & $52(34.66 \%)$ & $26(34.7 \%)$ & $26(34.7 \%)$ & \\
\hline \multicolumn{5}{|l|}{ Husband's education } \\
\hline Below diploma & $33(22 \%)$ & $17(22.7 \%)$ & $16(21.3 \%)$ & 0.977 \\
\hline Diploma & $52(34.66 \%)$ & $26(34.7 \%)$ & $26(34.7 \%)$ & \\
\hline Higher & $65(43.33 \%)$ & $32(42.7 \%)$ & $33(44 \%)$ & \\
\hline \multicolumn{5}{|l|}{ Occupation } \\
\hline Not working (housewife) & $107(71.34 \%)$ & $51(68 \%)$ & $56(74.4 \%)$ & 0.726 \\
\hline Working outside home & $43(28.66 \%)$ & $24(32 \%)$ & $19(25.3 \%)$ & \\
\hline
\end{tabular}

the researcher introduced herself completely and elaborated on the purpose of research for the participating women. Then a written letter of consent was obtained from all participants with all details of the research procedure. Participation was voluntary. All participants were asked not to mention their name and were all assured of the confidentiality of the information they provided. This research was approved by the committee of ethics at Hormozgan University of medical sciences.

\section{Data management and analysis}

To describe quantitative variables (i.e., age, HBM constructs), mean and standard deviation were used. To describe qualitative variables (i.e., age group, education, husband's education and occupation), frequency and relative frequency were used. To test the parametric hypotheses such as the normality of distribution and equal variance, Kolmogorov-Smirnov and Levene's test were used. Independent samples T-test was used then to compare the HBM constructs between the control and intervention groups as well as the adoption of GWs preventive behaviors between the two groups. Pairedsamples T-test was run to compare changes in the scores of the model constructs in each group in the pre-and post-test. ANCOVA was run to moderate and control the effect of the pretest scores on the posttest. Multiple linear regression analysis was used in the intervention group to test the effect of each model construct on the preventive behavior score. Behavior was used as the dependent variable and awareness and model constructs as the independent variables. All analyses were done in SPSS20.

\section{Results}

\section{Descriptive phase: socio-demographic characteristics}

The present quasi-experimental research was conducted on 150 women (75 in the intervention and 75 in the control group) between 17 and 42 years of age. The mean and standard deviation of the participants' age was $26.09 \pm 4.15$ and $28.35 \pm 6.6$ in the control and intervention groups, respectively. Concerning education, in both groups, the highest frequency was that of diploma. In the control and intervention groups, it was 38 (50.7\%) and 29 (38.7\%), respectively. As for occupation, in both groups, the highest frequency belonged to the housewives. 56 participants $(74.4 \%)$ of the control group and 51 of the intervention $(68 \%)$ were housewives. The other demographic variables are described in Table 1.

\section{Awareness and HBM scores in the pre- versus post-test}

In the pretest, the between-group difference was not statistically significant in terms of awareness and the HBM constructs $(p>0.05)$. However, in the posttest, the between-group difference was statistically significant in terms of the awareness score and HBM constructs, but not for the perceived benefits $(p<0.001)$. In the pretest, the behavior score in the intervention was $2.77 \pm 2.59$, which was increased to $3.73 \pm 0.52$ in the post-test. This difference was statistically significant. In the control group, the difference in the behavior score was not statistically significant in the pre- and posttest (Table 2). 
Table 2 Comparison of HBM constructs in the pre- and post-test in two research groups

\begin{tabular}{|c|c|c|c|c|}
\hline Variables & Groups & $\begin{array}{l}\text { Pre-test } \\
\text { (Mean } \pm \text { SD) }\end{array}$ & $\begin{array}{l}\text { Post-test } \\
\text { (Mean } \pm \text { SD) }\end{array}$ & $p$ value \\
\hline \multirow[t]{3}{*}{ Awareness } & Intervention & $14.21 \pm 5.26$ & $18.68 \pm 1.66$ & $<0.001$ \\
\hline & Control & $14.49 \pm 5.56$ & $15.55 \pm 1.36$ & 0.115 \\
\hline & $p$ value & 0.752 & $<0.001$ & \\
\hline \multirow{3}{*}{$\begin{array}{l}\text { Perceived sus- } \\
\text { ceptibility }\end{array}$} & Intervention & $18.71 \pm 5.52$ & $26.27 \pm 3.12$ & $<.001$ \\
\hline & Control & $18.52 \pm 6.4$ & $18.77 \pm 3.30$ & .717 \\
\hline & $p$ value & .844 & $<.001$ & \\
\hline \multirow{3}{*}{$\begin{array}{l}\text { Perceived sever- } \\
\text { ity }\end{array}$} & Intervention & $18.40 \pm 4.78$ & $23.84 \pm 3.05$ & $<.001$ \\
\hline & Control & $18.57 \pm 4.04$ & $19.16 \pm 3.09$ & .284 \\
\hline & $p$ value & .812 & $<.001$ & \\
\hline \multirow[t]{3}{*}{ Perceived barriers } & Intervention & $29.29 . \pm 8.57$ & $25.88 . \pm 5.27$ & $<.001$ \\
\hline & Control & $29.83 \pm 7.62$ & $28.89 \pm 4.52$ & .0770 \\
\hline & $p$ value & .687 & $<.001$ & \\
\hline \multirow{3}{*}{$\begin{array}{l}\text { Perceived ben- } \\
\text { efits }\end{array}$} & Intervention & $23.99 \pm 2.23$ & $24.32 \pm 0.47$ & .314 \\
\hline & Control & $23.79 \pm 3.43$ & $23.96 \pm 3.72$ & .716 \\
\hline & $p$ value & .693 & .343 & \\
\hline \multirow[t]{3}{*}{ Self-efficacy } & Intervention & $20.03 \pm 4.04$ & $23.12 \pm 1.95$ & $<.001$ \\
\hline & Control & $20.04 \pm 5.75$ & $20.39 \pm 2.29$ & .543 \\
\hline & $p$ value & .987 & .001 & \\
\hline \multirow[t]{3}{*}{ Behavior } & Intervention & $2.77 \pm 2.59$ & $3.73 \pm 0.52$ & .002 \\
\hline & Control & $2.61 \pm 1.24$ & $2.85 \pm 0.81$ & .227 \\
\hline & $p$ value & .630 & $<.001$ & \\
\hline
\end{tabular}

\section{Controlling the covariate effect of scores in the pretest}

In order to control and moderate the effect of scores in the pretest, an analysis of covariance (ANCOVA) was run. As reported in Table 3, the pretest scores were statistically significant covariates of perceived susceptibility (partial $\eta 2=0.058 ; p=0.003$ ), perceived barriers (partial $\eta 2=0.129 ; p<0.001$ ) and self-efficacy (partial $\eta 2=0.194$; $p<0.001)$. However, they were not statistically significant covariates of awareness, perceived severity, benefits and behavior. As the tabulated data show, the educational intervention significantly affected awareness (partial $\eta 2=0.394 ; p<0.001$ ), all model constructs (perceived susceptibility (partial $\eta 2=0.592 ; p<0.001$ ), severity (partial $\eta 2=0.522 ; p<0.001$ ), barriers (partial $\eta 2=0.129$; $p<0.001$ ), benefits (partial $\eta 2=0.186 ; p<0.001$ ), self-efficacy (partial $\eta 2=0.481 ; p<0.001)$ ) and the behavior (partial $\eta 2=0.394 ; p<0.001)$.

\section{Predictors of adopting GWs preventive behaviors}

A multivariate linear regression analysis was used to test the effect of each model construct on behavior. The dependent variable was GWs preventive behavior and awareness and other constructs were the independent variables. As it can be seen in Table 4, awareness, perceived susceptibility, severity and self-efficacy were the strong predictors of preventive behavior. The adjusted R2 value of 0.567 shows that the model explained $57 \%$ of changes in the behavior score of the intervention group.

\section{Discussion}

The present research investigated the effect of an educational intervention based on the HBM on adopting GWs preventive behaviors.

In the multivariate regression model, $\mathrm{R} 2$ was estimated at 0.57 . It shows that the independent variables within the model (i.e., knowledge and HBM constructs) accounted for $57 \%$ of the variance in the dependent variable (adoption of GWs preventive behaviors).

The intervention managed to significantly affect all constructs except for the perceived benefits. As the multivariate linear regression analysis showed, awareness, perceived susceptibility and severity, and self-efficacy were the significant predictors of adopting GWs preventive behaviors.

In most studies, the educational interventions based on the HBM directly addressed HPV infection and uterine cancer screening. Therefore, we compared our findings with theirs [33-36].

As the results showed, women's awareness both in the control and intervention groups was very low before the intervention. This was consistent with other studies showing that women's awareness of cervical cancer screening and HPV vaccination was low before the intervention [37-39]. Still, some other studies showed divergent findings as they reported a high level of awareness of cervical cancer and Pap test administration among women [40, 41]. These contradictory findings can be explained by participants' different demographic information, as Aweke et al. included educated women in their research, whose knowledge and awareness were certainly higher than the average population. Different purposes of research, different cultural backgrounds, and questionnaire items of different levels can partly account for contradictory findings. A systematic review attributed women's unawareness of cervical cancer in developing countries to the lack of well-organized cancer screening programs, sociocultural barriers, and inefficient awareness-raising media [42]. Regular educational campaigns by experienced medics are highly recommended along with formal mass media to raise women's awareness of GWs preventive behaviors.

The present findings show an increase in the awareness score of the intervention group compared to the control in the posttest. This attests to the effectiveness of the intervention. There were other works of research that confirmed these findings, as they showed an educational intervention could raise women's awareness of the Pap test administration [31, 43, 44]. 
Table 3 Analysis of covariance to adjust the pretest scores as a variable covariate

\begin{tabular}{|c|c|c|c|c|c|c|c|}
\hline Variables & Source & Sum of squares & df & Mean square & F-value & $p$ value & $\begin{array}{l}\text { Partial } \\
\text { eta } \\
\text { squared }\end{array}$ \\
\hline \multirow[t]{4}{*}{ Awareness } & Pretes & .093 & 1 & .093 & .040 & .842 & .000 \\
\hline & Posttest & 367.613 & 1 & 367.613 & 157.634 & $<.001$ & .517 \\
\hline & Error & 342.814 & 147 & 2.332 & & & \\
\hline & \multicolumn{7}{|c|}{ R Squared $=.518$ (Adjusted R Squared $=.511$ ) } \\
\hline \multirow[t]{4}{*}{ Perceived susceptibility } & Pretest & 88.273 & 1 & 88.273 & 9.002 & .003 & .058 \\
\hline & Posttest & 2091.104 & 1 & 2091.104 & 213.239 & $<.001$ & .592 \\
\hline & error & 1441.541 & 147 & 9.806 & & & \\
\hline & \multicolumn{7}{|c|}{ R Squared $=.603$ (Adjusted R Squared $=.598$ ) } \\
\hline \multirow[t]{4}{*}{ Perceived severity } & Pretest & 8.403 & 1 & 8.403 & 1.639 & .203 & .011 \\
\hline & Posttest & 824.284 & 1 & 824.284 & 160.754 & $<.001$ & .522 \\
\hline & error & 753.757 & 147 & 5.128 & & & \\
\hline & \multicolumn{7}{|c|}{ R Squared $=.524$ (Adjusted R Squared $=.518$ ) } \\
\hline \multirow[t]{4}{*}{ Perceived benefits } & Pretest & .000 & 1 & .000 & .003 & .960 & .000 \\
\hline & Posttest & 4.851 & 1 & 4.851 & 33.639 & $<.001$ & .186 \\
\hline & error & 21.200 & 147 & .144 & & & \\
\hline & \multicolumn{7}{|c|}{ R Squared $=.187$ (Adjusted R Squared $=.175)$} \\
\hline \multirow[t]{4}{*}{ Perceived barriers } & Pretest & 397.798 & 1 & 397.798 & 21.760 & $<.001$ & .129 \\
\hline & Posttest & 1243.343 & 1 & 1243.343 & 68.014 & $<.001$ & .316 \\
\hline & error & 2687.269 & 147 & 18.281 & & & \\
\hline & \multicolumn{7}{|c|}{ R Squared $=.373$ (Adjusted R Squared $=.364$ ) } \\
\hline \multirow[t]{4}{*}{ Self-efficacy } & Pretest & 130.137 & 1 & 130.137 & 35.323 & $<.001$ & .194 \\
\hline & Posttest & 280.681 & 1 & 280.681 & 76.186 & $<.001$ & .481 \\
\hline & error & 302.570 & 147 & 3.684 & & & \\
\hline & \multicolumn{7}{|c|}{ R Squared $=.461$ (Adjusted R Squared $=.433$ ) } \\
\hline \multirow[t]{4}{*}{ Behavior } & Pretes & .055 & 1 & .055 & .115 & .735 & .001 \\
\hline & Posttest & 45.524 & 1 & 29.094 & 61.100 & $<.001$ & .394 \\
\hline & error & 69.999 & 147 & .476 & & & \\
\hline & \multicolumn{7}{|c|}{ R Squared $=.403$ (Adjusted R Squared $=.384$ ) } \\
\hline
\end{tabular}

Table 4 Multivariate regression analysis of the predictors of behavior in the intervention group based on the model constructs

\begin{tabular}{|c|c|c|c|c|c|c|}
\hline \multirow[t]{2}{*}{ Variables } & \multirow[t]{2}{*}{ B } & \multicolumn{2}{|c|}{ 95.0\% confidence Interval for B } & \multirow{2}{*}{$\begin{array}{l}\text { Standardized } \\
\text { coefficients beta }\end{array}$} & \multirow[t]{2}{*}{$\mathrm{t}$} & \multirow[t]{2}{*}{$p$ value } \\
\hline & & Lower bound & Beta & & & \\
\hline Awareness & .086 & .035 & .137 & .231 & 3.353 & .001 \\
\hline Perceived susceptibility & .068 & .034 & .103 & .413 & 3.893 & $<0.001$ \\
\hline Perceived severity & .079 & .038 & .120 & .315 & 3.779 & $<0.001$ \\
\hline Perceived Self-efficacy & .096 & .045 & .146 & .296 & 3.735 & $<0.001$ \\
\hline Perceived benefits & .060 & -.193 & .314 & .031 & .471 & .638 \\
\hline Perceived barriers & -.020 & -.031 & .044 & .132 & 1.638 & .104 \\
\hline Adjusted R Square $=.567$ & $.589=\mathrm{R}$ Square & & & & & \\
\hline
\end{tabular}

Our research showed no statistically significant difference between the two groups before the intervention in terms of perceived susceptibility. This difference, however, was significant after the intervention. Similarly, a number of other studies showed that educational interventions could change women and girls' perceived susceptibility to pap smear screening and HPV infection [45-47]. Contrary to our findings, an educational intervention was not effective in changing perceived susceptibility in another study [48]. Differences in outcomes 
from these studies may be due to different purposes of research, as the study by Park et al. used a short-term one-hour educational intervention aiming to increase participation in the Pap test as the researchers perceived the time of intervention inadequate for changing attitude. Also, Park et al. did not use the HBM in their study. Rather, their educational intervention was developed based on the cognition-emotion theory.

In our research, perceived susceptibility was a strong predictor of women's preventive behavior. Education can be argued to increase women's awareness of the symptoms, side effects, and preventive measures of GWs. This can increase women's susceptibility to the infection. Researchers believe to be motivated to show a particular healthy behavior, people need to be aware of the adverse effects of a disease or its effect on their awareness [49]. Resenstock (as cited in Ningrum [50]) maintained that those who perceive themselves more susceptible to a disease pay more attention to preventive and medical services [50]. In two relevant studies, perceived susceptibility showed to predict women's adoption of healthy behavior (cancer screening and HPV vaccination) [51, 52]. We can argue that systematic and effective educational interventions made by experienced health staff can significantly affect women's perceived susceptibility to GWs and other sexually transmitted diseases.

Moreover, our findings showed a significant increase in perceived severity scores in the intervention group in the posttest. Similarly, two other studies proved the effectiveness of educational interventions in women's perceived severity of cervical cancer screening and their intention of HPV vaccination [31, 46]. In contrast to our findings, another study reported the ineffectiveness of an educational intervention in changing women's perceived severity of cervical cancer screening [48]. This difference can be partly explained by the different purposes of research, types of intervention and participants' demographic features.

Our research showed that the mean perceived benefits score was not significantly different across the control and intervention groups. Also, this construct did not have any statistically significant effect on women's preventive behaviors, which was quite expected as our intervention had no effect on this construct. On the contrary, in a number of other studies, the educational intervention showed to significantly affect the perceived benefits construct $[31,53]$. We can argue that probably the benefits of adopting GWS preventive behaviors do not emerge immediately after the intervention or shortly afterwards. Thus, women are not capable of perceiving the real benefits of the target behavior. It is likely that during the intervention, the educational content did not manage to affect this construct. A short-term follow-up and the high mean score of perceived benefits before the intervention are among other reasons for this finding. It seems that designing long-term educational interventions with a longer follow-up is more realistic.

Another finding was that the mean score of perceived barriers was decreased in the intervention group compared to the control in the post-test. Similarly, in some other studies, the mean score of perceived barriers was lowered after the educational intervention [31, 48]. Hyacinth et al. reported that perceived barriers was the strongest predictor of administering the Pap test. This can show that removing barriers to the administration of the Pap test can increase the rate of administering the test [54]. Contrary to the present findings, in another study, the educational intervention had no effect on the mean score of perceived barriers [46]. In our research, though the mean score of perceived barriers was reduced in the intervention group, it had no effect on women's healthy behavior. The absence of any increase in the perceived benefits score can be possibly another explanation for this. Probably, when women do not perceive the benefits of behavior, the barriers to adopting the healthy behavior are highlighted, and, thus, women do not make any attempts to lower the barriers.

Our findings showed an increase in the mean score of self-efficacy in the intervention group in the posttest. Similar to the present findings, some other studies showed that high self-efficacy managed to increase the intention of HPV vaccination and administering the Pap test $[48,53]$. Exploration of the association between self-efficacy and healthy behavior showed that the former strongly affected the latter. It is less likely that someone with a lower self-efficacy changes an already established behavior or show a new healthy behavior [55]. The increased self-efficacy and its predictive effect on the adoption of GWs preventive behaviors were quite expected in this research. The participants tried to use a systematic and theory-based educational intervention specifically beside the other constructs as self-efficacy plays a significant role in the adoption of a healthy behavior such as HPV vaccination and administration of the Pap test $[55,56]$.

Our research showed an increase in the mean score of women's self-reported behaviour in the intervention group compared to the control. This proves the effectiveness of the educational intervention based on the HBM in adopting GWs preventive behavior. A number of other studies also confirmed this finding that an educational intervention can positively affect women's healthy behavior $[43,57]$. Arguably, raising awareness through affecting other HBM variables can positively affect women's adoption of healthy behavior. 


\section{Limitations, strengths and future research}

The small sample size in the present research limits the generalization of results to women in other provinces and target populations, including men. To increase the generalizability of results, future research is required with a larger sample with male and female participants both in different geographical areas with different sociocultural features. GWs preventive behavior needs to be explored more thoroughly. The absence of any similar research limits the comparability of results and decision-making in the field. The short-term follow-up of women is another limitation of this research. Thus, it is recommended that the participants be followed for at least a year to check the consistency of the behavior. Besides these limitations, there are certain strengths too. For one, The HBM is a systematic model to explain a healthy preventive behavior. This model encompasses key concepts in the intervention and elaborates on them [46]. Our research can act as a basis of comparing other studies and models in near future. It also provides key information for policy-makers about the significance of health education in the adoption of preventive health behavior including GWs.

\section{Conclusion}

Our results showed that women's awareness of different aspects of GWs was low. This low awareness was a warning for the promotion of healthy behaviors among women. That is because a low awareness of women is followed by a lower perceived severity of the GWs. These all make women unaware of the benefits of the above-mentioned healthy behavior. When they fail to perceive the benefits, they perceive more barriers and make no attempts to remove them. All these factors together weaken women's capability of and determination in showing the desired healthy behavior. Our findings showed that an educational intervention based on the HBM can increase the acceptability of GWs preventive behaviors among women. The education should be provided by experienced experts regularly at short intervals in all healthcare centers. We, in particular, hope to implement systematic educational programs in the light of health education and promotion models to promote GWs preventive behaviors. Health education specialists and local media can be actively involved in the success of these educational programs.

\section{Supplementary Information}

The online version contains supplementary material available at https://doi. org/10.1186/s13027-021-00408-w.

Additional file 1. The Educational Intervention Content.

\section{Acknowledgements}

The authors would like to thank Hormozgan University of medical science as their financial support. The authors would also like to express their gratitude to the participants for their sincere cooperation in this study

\section{Authors' contributions}

Z.H, designed the study, supervised data collection, analyzed the data and reviewed the manuscript.; SD, designed the study, collected data, analyzed the data drafted the manuscript and critically reviewed the manuscript, T.A; designed the study, reviewed the manuscript., SH.M, analyzed the data and reviewed the manuscript, A.A, N.S, ZH reviewed the manuscript, all authors read and approved the final manuscript.

Funding

This research received a grant from Hormozgan university of medical science.

Availability of data and materials

The datasets used and analysed during the current study are available from the corresponding author on reasonable request.

\section{Declarations}

\section{Ethics approval and consent to participate}

This research was approved by Hormozgan University of medical sciences (\#IR.HUMS.REC.1398.112). All participants were required to sign an informed consent and were informed they could withdraw in any step of the research if they desired. For the participants below 18 years of age an informed consent was obtained from parents. We can confirm that all methods were performed in accordance with the relevant guidelines and regulations of research ethics.

\section{Consent for publication}

Not applicable.

\section{Competing interests}

The authors have no competing interests to declare.

\section{Author details}

${ }^{1}$ Social Determinants in Health Promotion Research Center, Hormozgan Health Institute, Hormozgan University of Medical Sciences, Bandar Abbas, Iran. ${ }^{2}$ Student Research Committee, Hormozgan University of Medical Sciences, Bandar Abbas, Iran. ${ }^{3}$ Cardiovascular Research Center, Hormozgan University of Medical Sciences, Bandar Abbas, Iran. ${ }^{4}$ Mother and Child Welfare Research Center, Faculty of Nursing and Midwifery, Hormozgan University of Medical Sciences, Bandar Abbas, Iran. ${ }^{5}$ Infectious and Tropical Diseases Research Center, Hormozgan Health Institute, Hormozgan University of Medical Sciences, Bandar Abbas, Iran.

Received: 21 July 2021 Accepted: 22 November 2021

Published online: 11 December 2021

References

1. Cheng L, Wang Y, Du J. Human papillomavirus vaccines: an updated review. Vaccines. 2020;8(3):391. 
2. Ruiz-López T, Sen S, Jakobsen E, Tropé A, Castle PE, Hansen BT, Nygård M. FightHPV: design and evaluation of a mobile game to raise awareness about human papillomavirus and nudge people to take action against cervical cancer. JMIR Ser Games. 2019;7(2):e8540.

3. Egawa N, Doorbar J. The low-risk papillomaviruses. Virus Res. 2017;231:119-27.

4. Mann LM, Llata E, Flagg EW, Hong J, Asbel L, Carlos-Henderson J, Kerani RP, Kohn R, Pathela P, Schumacher C. Trends in the prevalence of anogenital warts among patients at sexually transmitted disease clinics-Sexually Transmitted Disease Surveillance Network, United States, 2010-2016. J Infect Dis. 2019;219(9):1389-97.

5. Cho C-Y, Lo Y-C, Hung M-C, Lai C-C, Chen C-J, Wu K-G. Risk of cancer in patients with genital warts: a nationwide, population-based cohort study in Taiwan. PLOS ONE. 2017;12(8):e0183183.

6. Nordenvall C, Chang ET, Adami HO, Ye W. Cancer risk among patients with condylomata acuminata. Int J Cancer. 2006;119(4):888-93.

7. Sigurgeirsson $B$, Lindelöf $B$, Eklund G. Condylomata acuminata and risk of cancer: an epidemiological study. Br Med J. 1991;303(6798):341-4.

8. Najafi F, Hematti M, Jalilian N. Epidemiologic study of genital warts among women in Kermanshah Province, Iran. Acta Med Mediterr. 2016;32:1955-8

9. Buenconsejo L, Kothari-Talwar S, Yee K, Kulkarni A, Lara N, Roset M, Giuliano AR, Garland S. Estimating the burden of illness related to genital warts in the Philippines: a nationally representative cross-sectional study. Infect Agents Cancer. 2019;14(1):26.

10. Khopkar US, Rajagopalan M, Chauhan AR, Kothari-Talwar S, Singhal PK, Yee K, Kulkarni A, Lara N, Roset M, Giuliano AR. Prevalence and burden related to genital warts in India. Viral Immunol. 2018;31(5):346-51.

11. Dareng EO, Adebamowo SN, Famooto A, Olawande O, Odutola MK, Olaniyan Y, Offiong RA, Pharoah PP, Adebamowo CA. Prevalence and incidence of genital warts and cervical Human Papillomavirus infections in Nigerian women. BMC Infect Dis. 2019;19(1):27.

12. Khodakarami N, Clifford GM, Yavari P, Farzaneh F, Salehpour S, Broutet N, Bathija H, Heideman DA, van Kemenade FJ, Meijer CJ. Human papillomavirus infection in women with and without cervical cancer in Tehran, Iran. Int J Cancer. 2012;131(2):E156-61.

13. Malakouti J, Mirghafourvand M, Gorbani M, Poormehr HS, Shahrak SP, Shabiri MJ. Incidence of Human Papilloma Virus (HPV) infection and its relevant factors among women referring to Alzahra Therapeutic-Educational Center of Tabriz, September 2013 to March 2014. Iran J Obstet Gynecol Infert. 2016;18(185):16-22.

14. Jamdar F, Farzaneh F, Navidpour F, Younesi S, Balvayeh P, Hosseini M, Ghodssi-Ghasemabadi R. Prevalence of human papillomavirus infection among Iranian women using COBAS HPV DNA testing. Infect Agents Cancer. 2018;13(1):1-5.

15. Soori T, Hallaji Z, Noroozi-Nejad E. Genital warts in 250 Iranian patients and their high-risk sexual behaviors. Arch Iran Med. 2013;16(9):518-20.

16. Shafaghi B, Jarollahi A, Yousefzadeh B, Ameri A, Moghadam S, Mostafavi M. Human papilloma virus prevalence and types among Iranian women attending regular gynecological visits. Rep Radiother Oncol. 2013;1(2):73-9

17. Lacey CJ, Lowndes CM, Shah KV. Burden and management of non-cancerous HPV-related conditions: HPV-6/11 disease. Vaccine. 2006;24:S35-41.

18. Kjær SK, Trung Nam T, Sparen P, Tryggvadottir L, Munk C, Dasbach E, Liaw K-L, Nygård J, Nygård M. The burden of genital warts: a study of nearly 70,000 women from the general female population in the 4 Nordic countries. J Infect Dis. 2007;196(10):1447-54.

19. Qaderi K, Mirmolaei ST, Geranmayeh M, Hasani SS, Farnam F. Iranian women's psychological responses to positive HPV test result: a qualitative study. BMC Womens Health. 2021;21(1):1-11.

20. Pakpour Hajiagha A, Mohammadi Zeidi I, Mohammadi ZB. The Impact of health education based on theory of planned behavior on the prevention of aids among adolescents. Iran J Nurs (2008-5923). 2012;25(78):1-13.

21. Roozbeh N, Safari Moradabadi A, Dadipoor S. Evaluation of awareness and high-risk behavior associated with genital wart in married female students. Ann Trop Med Public Health. 2017;10(6):1704-8.

22. Nekooi M, Ayazi S, Gandomi M, Moosavi SG, Fakhri A. Level of Knowledge about Human Papillomavirus Infection among Women of Kashan City, Iran. Int Arch Health Sci. 2016;3:7-12.
23. Bakhtari Aqdam F, Nuri Zadeh R, Sahebi L. Effect of education based on Health Belief Model on Believe promotion and screening behaviours of breast cancer among women reffered to Tabriz health centers. Medl J Tabriz Uni Medl Sci. 2012;2012(33):25-31.

24. Leung W, Chan P, Lau K, Ho K. The prevalence of human papilloma virus in the anal region of male Chinese attendees in three public sexually transmitted disease clinics in Hong Kong. Hong Kong J Dermatol Venereol. 2011;19(1):6-13.

25. Khani Jeihooni A, Ghaedi R, Kashfi SM, Khiyali Z. Effect of education based on the health belief model in the prevention of sexually transmitted diseases in couples participating in premarriage training classes. J Educ Community Health. 2018;4(4):4-12.

26. Zhao J, Song F, Ren S, Wang Y, Wang L, Liu W, et al. Predictors of condom use behaviors based on the Health Belief Model (HBM) among female sex workers: a cross-sectional study in Hubei Province, China. PloS one. 2012;7(11):e49542.

27. Hazavehei S, Sharifirad G, Mohabi S. The effect of educational program based on health belief model on diabetic foot care. Int J Diabetes Dev Ctries. 2007;27(1):18-23.

28. Rosenstock IM. Historical origins of the health belief model. Health Educ Monogr. 1974;2(4):328-35.

29. Feyisa GC, Temesgen H. Perceived benefits and barriers toward cervical cancer screening among women $\geq 15$ years in Arsi Zone, Southeastern Ethiopia: application of the health belief model in a community-based cross-sectional study. J Cancer Res Pract. 2019;6(1):7.

30. Blomberg M, Friii S, Munk C, Bautz A, Kjaer SK. Genital warts and risk of cancer: a Danish study of nearly 50000 patients with genital warts. J Infect Dis. 2012;205(10):1544-53.

31. Khiyali Z, Asadi R, Ghasemi A, Khani JA. The Effect of Educational intervention base on Health Belief Model on performing Pap smears in women of Fasa city. Iran J Health Educ Health Promot. 2017;5(4):304-10.

32. Farshbaf-Khalili A, Shahnazi M, Salehi-Pourmehr H, Faridvand F, Asgarloo Z. Behavioral prevention regarding sexually transmitted infections and its predictors in women. Iran Red Crescent Med J. 2014;16(8):e18346.

33. Kohan S, Taeri K. Effect of educational intervention based on perceived benefits and barriers on human papillomavirus inoculation in vulnerable women: application of health belief. Iran J Obstet Gynecol Infertility Model. 2020;23(7):78-87.

34. Ebrahim Mahmoud A, Abdelhakeem Aboud S, Kamal AF. Effect of the educational package based on health belief model on nursing students' knowledge and attitude regarding human papillomavirus and cervical cancer. J Nurs Sci Benha Univ. 2021;2(2):809-28.

35. Mora AS, Madrigal JM, Jordan L, Patel A. Effectiveness of an educational intervention to increase human papillomavirus knowledge in high-risk minority women. J Lower Genital Tract Dis. 2018;22(4):288-94.

36. Barrios MC, Rodríguez LS, Pachón CM, Lugo EA. Educational intervention on human papillomavirus in university students. Indian J Community Med. 2019;44(3):213.

37. Touch S, Oh J-K. Knowledge, attitudes, and practices toward cervical cancer prevention among women in Kampong Speu Province, Cambodia. BMC Cancer. 2018;18(1):1-8.

38. Hussain S, Nasare V, Kumari M, Sharma S, Khan MA, Das BC, Bharadwaj M. Perception of human papillomavirus infection, cervical cancer and HPV vaccination in North Indian population. PLoS ONE. 2014;9(11):e112861.

39. Ghosh S, Mallya SD, Shetty RS, Pattanshetty SM, Pandey D, Kabekkodu SP, Satyamoorthy K, Kamath VG. Knowledge, attitude and practices towards cervical cancer and its screening among women from tribal population: a community-based study from Southern India. J Racial Ethnic Health Disparities. 2021:8(1):88-93.

40. Anene-Okeke CG, Aluh DO, Okorie UH. Knowledge, attitudes and practice of cervical cancer prevention among student health professionals in Nigeria. Asian Pac J Cancer Care. 2019;4(4):125-30.

41. Aweke YH, Ayanto SY, Ersado TL. Knowledge, attitude and practice for cervical cancer prevention and control among women of childbearing age in Hossana Town, Hadiya zone, Southern Ethiopia: community-based cross-sectional study. PLoS ONE. 2017;12(7):e0181415.

42. Devarapalli P, Labani S, Nagarjuna N, Panchal P, Asthana S. Barriers affecting uptake of cervical cancer screening in low and middle income countries: a systematic review. Indian J Cancer. 2018;55(4):318.

43. Shobeiri F, Javad M, Parsa P, Roshanaei G. Effects of group training based on the health belief model on knowledge and behavior regarding the 
pap smear test in Iranian women: a quasi-experimental study. Asian Pac J Cancer Prevent. 2016;17(6):2871-6.

44. Liu C-R, Liang H, Zhang X, Pu C, Li Q, Li Q-L, Ren F-Y, Li J. Effect of an educational intervention on HPV knowledge and attitudes towards HPV and its vaccines among junior middle school students in Chengdu, China. BMC Public Health. 2019;19(1):1-9.

45. Samami E, Seyedi-Andi SJ, Bayat B, Shojaeizadeh D, Tori NA. The effect of educational intervention based on the health belief model on knowledge, attitude, and function of women about Pap smear test at Iranian health centers: a randomized controlled clinical trial. J Educ Health Promot. 2021;10:22.

46. Grandahl M, Rosenblad A, Stenhammar C, Tydén T, Westerling R, Larsson M, Oscarsson M, Andrae B, Dalianis T, Nevéus T. School-based intervention for the prevention of HPV among adolescents: a cluster randomised controlled study. BMJ Open. 2016;6(1):e009875.

47. Vasheghani F, Majlesi F, Mahmoudi M, Shojaeezadeh D. Effect of educational intervention based on Health Belief Model on knowledge and attitude about pap smear test among female secondary school teachers in district 11 of Tehran. J Sch Public Health Inst Public Health Res. 2012:10(2):39-46.

48. Park S, Chang S, Chung C. Effects of a cognition-emotion focused program to increase public participation in Papanicolaou smear screening. Public Health Nurs. 2005;22(4):289-98.

49. Karimy M, Azarpira H, Araban M. Using health belief model constructs to examine differences in adherence to pap test recommendations among Iranian women. Asian Pac J Cancer Prevent: APJCP. 2017;18(5):1389.

50. Ningrum DNS. Path Analysis Hubungan Pendidikan dan Konstruk Health Belief Model dengan Kinerja Kader Pada Pengendalian Kasus Tuberkulosis Di Puskesmas Baki Kabupaten Sukoharjo. UNS (Sebelas Maret University); NIM / NIP S021408013, Sumber: UNS-F.Pascasarjana Progdi.Imu Kesehatan Masyarakat Minat Epidemiologi dan Biostatistika-S021408013. 2016.

51. Fitriani Y, Mudigdo A, Andriani RB. Health belief model on the determinants of human papilloma virus vaccination in women of reproductive age in Surakarta, Central Java. J Health Promot Behav. 2018;3(1):16-26.

52. Nugrahani RR, Budihastuti UR, Pamungakasari EP. Health belief model on the factors associated with the use of hpv vaccine for the prevention of cervical cancer among women in Kediri, East Java. J Epidemiol Public Health. 2017;2(1):70-81.

53. Park S, Jang I, Lee JL, Kim Y. Factors Affecting Vaccination Status of Female Adolescents Subject to the Korean National HPV Immunization Program: focusing on Mothers' HPV Knowledge and Heath Beliefs of HPV Vaccines. J Korean Soc Sch Health. 2020;33(1):58-66.

54. Hyacinth HI, Adekeye OA, Ibeh JN, Osoba T. Cervical cancer and pap smear awareness and utilization of pap smear test among Federal civil servants in North Central Nigeria. PLoS ONE. 2012;7(10):e46583.

55. Karimy M, Gallali M, Niknami S, Aminshokravi F, Tavafian S. The effect of health education program based on Health Belief Model on the performance of Pap smear test among women referring to health care centers in Zarandieh. J Jahrom Univ Med Sci. 2012;10(1):53-9.

56. He C. Use of the health belief model to understand HPV vaccine behavior in female undergraduates: Eastern Michigan University; Master Of Science in Community Health Education Thesis Committee:Megan Sterling, ChairSusan McCarthy, Andrew Cornett. December 15, 2015.

57. Bahmani A, Gharib A, Rahmani K, Ahmadian F, Alizadeh Z, Akhtar B. Effect of health belief model education on the participation of rural women in papsmear test. J Nurs Educ. 2016;4(5):34-40.

\section{Publisher's Note}

Springer Nature remains neutral with regard to jurisdictional claims in published maps and institutional affiliations.

Ready to submit your research? Choose BMC and benefit from:

- fast, convenient online submission

- thorough peer review by experienced researchers in your field

- rapid publication on acceptance

- support for research data, including large and complex data types

- gold Open Access which fosters wider collaboration and increased citations

- maximum visibility for your research: over $100 \mathrm{M}$ website views per year

At BMC, research is always in progress.

Learn more biomedcentral.com/submissions 